\title{
PROPELLER JET FLOW, PILE SUPPORTED PIERS AND SEA BED INTERACTION
}

\author{
R. İlayda Tan ${ }^{1}$, Yalçın Yüksel ${ }^{2}$ and Yeşim Çelikoğlu ${ }^{3}$
}

\begin{abstract}
In maritime trade, from all over the world, transportation performed over the seas has been rapidly increasing due to high technological improvements leading the ships to have huge power and high speeds. The approach of even the big ships to the piers is now done by using the ship's own engine power without the help of tugs because of the operation and economic reasons. However; this has been observed to cause local scour around the piers. Local scour commonly defined as the scour which is occurred in the immediate vicinity of the hydraulic structures due to the direct impact of the structure on the flow. It is very important to reduce local scour caused by ships propeller jets. A thorough understanding of the erosion of the bed due to local scour remains a challenge since it is associated with a highly turbulent flow field. The propeller jet has 3D flow area and high velocities. The erosion problem around the berthing structures due to propeller jet can occur in three ways. These are; a) On a slope, b) At the bottom of vertical wall, c) Around piles. In this study, propeller jet flow was considered to investigate scour formations around piles with non-cohesive sediment bed. The scour mechanism induced by propeller jet with and without pile conditions were investigated experimentally and their comparisons were made. Because there was not enough study for the scouring process for pile type berthing structures under propeller jet flow in the literature.
\end{abstract}

Keywords: Propeller Jet Flow, Pile, Local Scour

\section{INTRODUCTION}

\section{A) JET MECHANISM}

Propeller induced scour problems have been investigated experimentally using physical models such as Albertson et al. (1951), Chin et al. (1996), Yuksel et al., (2012), Hong et al. (2013). Most investigations carried out with circular wall jet instead of a using propeller jet to avoid complexity flow around the propeller in the first place. Albertson (1977) classified diffusion under jet conditions into two categories named the zone of flow establishment (ZFE) and the zone of established Flow (ZEF) seen in Fig 1.

The velocity profile of a submerged water jet from an orifice varies also according to Gaussian normal probability function at each cross section (Fig. 1). In the zone of flow establishment the maximum velocity is constant while the lateral distribution is expanding. The region with constant maximum velocity has a pronounced potential core. The lateral section of potential core is contracting due to the turbulent mixing between the core and the surrounding fluid. In the zone of established flow, the maximum velocity starts to decay along the rotation axis. In this zone, entrainment of the surrounding fluid is balanced by reduction in the jet velocity. In addition, the water jet was symmetrical about the central axis (Albertson et al., 1951).

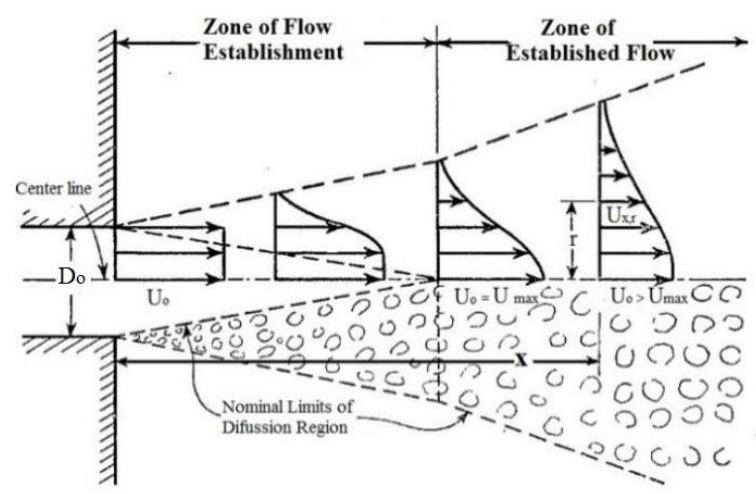

Figure 1. Schematized representation of a diffusing jet from an orifice (Albertson et al., 1951).

${ }^{1}$ Civil Engineering Department, Coastal and Harbour Engineering Laboratory, Yıldız Technical University, İstanbul, Davutpasa Campus H-Blok1-17, 34210, Turkey

2 Civil Engineering Department, Coastal and Harbour Engineering Laboratory, Yıldız Technical University, İstanbul, Davutpasa Campus H-Blok1-17, 34210, Turkey

${ }^{3}$ Civil Engineering Department, Coastal and Harbour Engineering Laboratory, Yıldız Technical University, İstanbul, Davutpasa Campus H-Blok1-17, 34210, Turkey 
However, the velocity for a propeller jet distribution also differs from any other type of jets. A rotating ship propeller generates a turbulent jet, with axial, radial, and tangential velocity components. The cross-sectional velocity distribution of a propeller within the zone of ZFE has two-peak ridges as seen in Fig 2. In the ZEF mean axial velocity profile defined as a Gaussian normal distribution and the maximum velocity is constant while the lateral distribution is expanding.

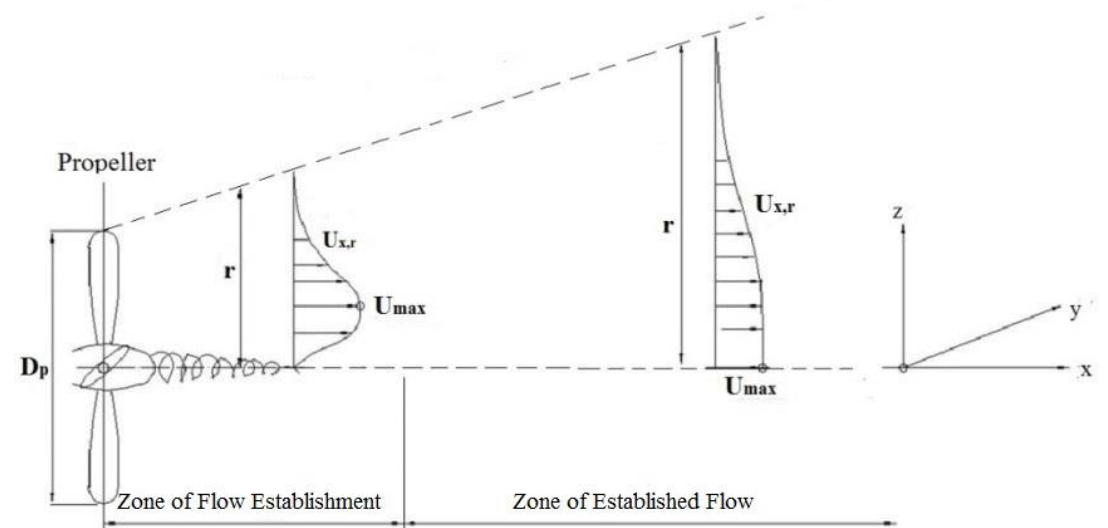

Figure 2. Velocity distribution induced by a propeller jet (Lam et al., 2011).

\section{B) EVOLUATION OF THE SCOUR MECHANISM}

In this study, the scour profiles are obtained for each completed experiments and all scouring tests are recorded during the processes to understand the evoluation of local scour under propeller jet mechanism with and without pile obstruction cases.

\section{a) Scouring Process Without Pile Obstruction}

The observations of the scouring process during the experiments without pile cases were showed similar formations with the previous studies in the literature. Hong et al. (2013) were defined four different stages for the evolution of a typical scouring process as initial, developing, stabilization and asymptotic stages as seen in Fig. 3.
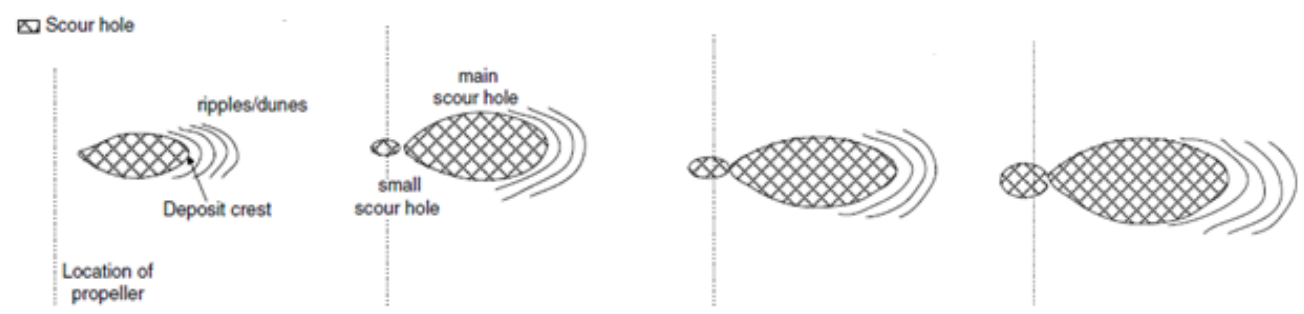

Figure 3. Schematic diagram for scouring processes (Hong et al., 2013).

These four stages were observed in the present study as seen in Fig. 4. First initial stage, primary scour hole formed with small ripples. Then a small scour hole was formed beneath the propeller while primary hole deepen at the developing stage. During stabilization stage small and primary scour increases and the distance between them decrease. The last asymptotic stage both small and primary scour merged and remain still.

\section{b) Scouring Process with Pile Obstruction}

The pile structure causes local flow accelerations and vertical down-flow at the face of pile due to the jet flow's impinging onto the pile.

Van Rijn (2013) characterized flow pattern around a cylindrical pile as;

-water surface roller in front of pile,

- down-flow in front of pile,

-vortex-shedding in separation zone,

-wake flow downstream of pile and generation of horseshoe-vortices in scour hole.

Flow pattern and scouring mechanism are very complicated, and the complexity of flow increases with the development of the scour hole as seen in Fig. 5. 

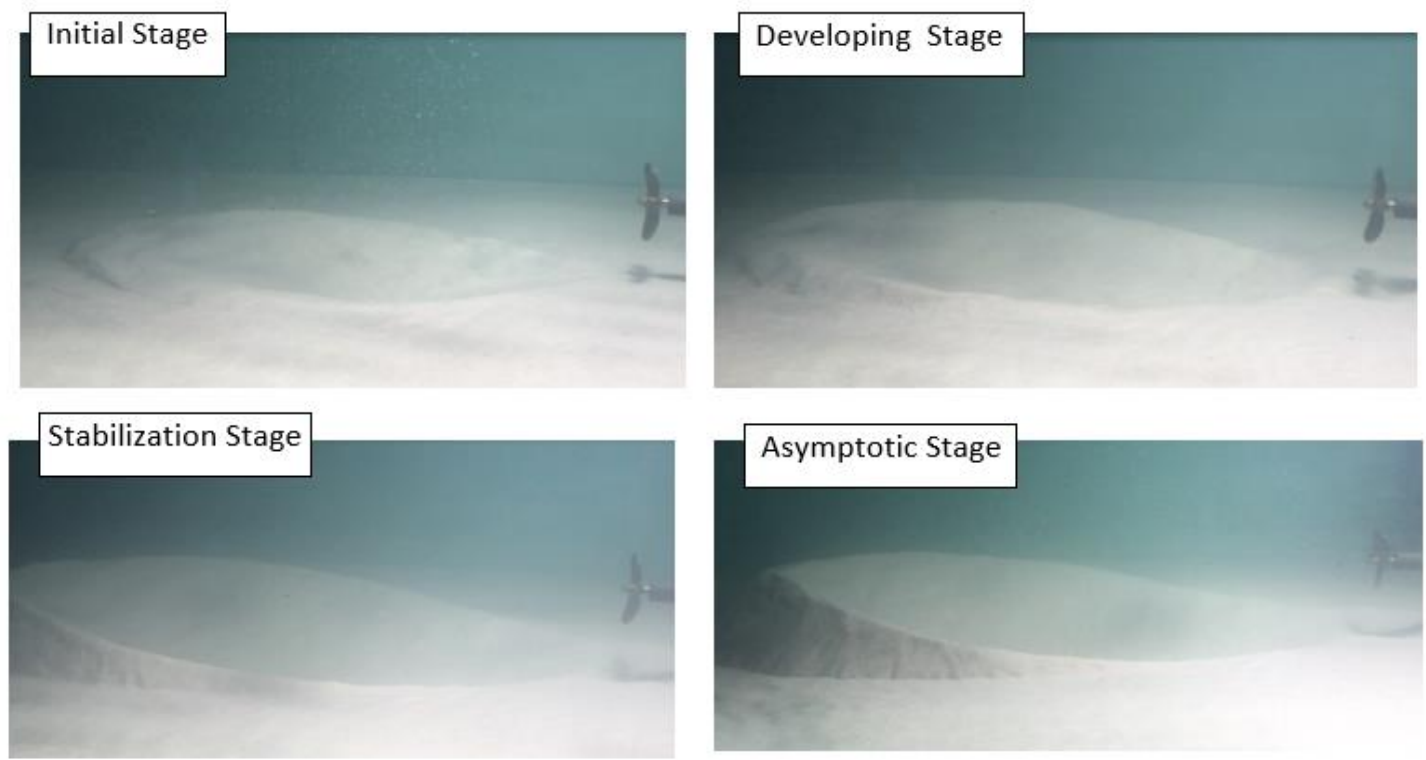

Figure 4. Evoluation of the scour profile without pile obstruction under propeller jet.

Local scour around pile is caused due to down-flow at the face of pile (upstream of the pile) and horseshoe vortex at the base of pile. Mostly, down-flow is the primary cause of a scour. The horseshoe vortex develops due to the separation of flow at the edge of the scour hole upstream rolls to form a helical flow, which is similar to the ground roller downstream of a dune crest. The horseshoe vortex is a consequence of scour, not the primary cause, pushing the down-flow inside the scour hole closer to the pile. Separation of the flow at the sides of the pile also creates so called wake vortices. These vortices are unstable and shed disorderly from each side of the pile. They act as small tornadoes lifting the sediment from the bed to form a scour hole downstream of the pile (Van Rijn, 2013).

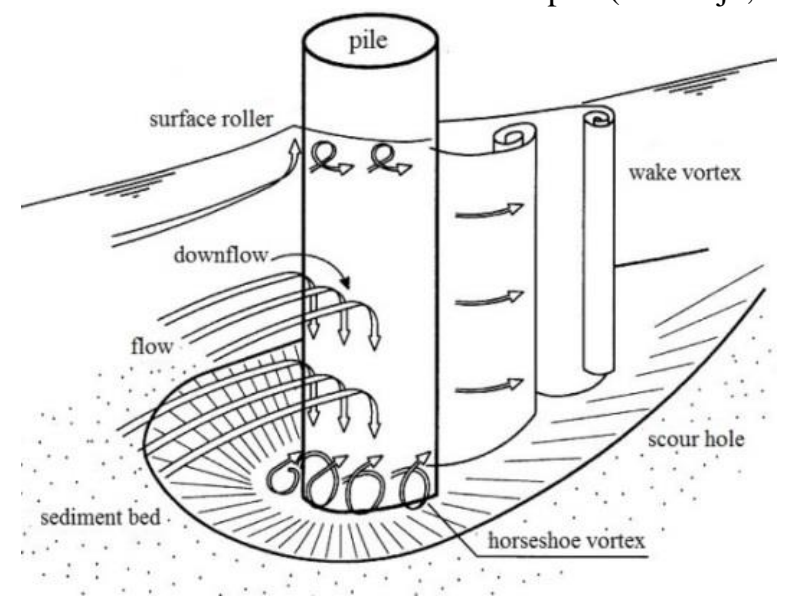

Figure 5. Flow pattern and scour at the base of pile (Van Rijn, 2013).

Chin et al. (1996) also identified mechanism of scour induced by jet into two categories; 'Pile obstruction mechanism' occurred due to impinging of jet flow onto the pile and 'Jet diffusion mechanism' formed the scour hole under jet's diffusive velocity which was decreasing from the exit of the jet. They stated for pile existing conditions that down-flow due to the impinging and latter horseshoe vortex were weak at the beginning then down-flow velocity increased with the deflected flow into scour hole while scour hole at the pile was developed.

They also characterized evoluation of scour hole with the impact of pile obstruction into 4 types according to $\mathrm{X} / \mathrm{D}_{\mathrm{o}}$ and densimetric Froude number $\left(\mathrm{Fr}_{\mathrm{d}}\right)$ under circular jet flow. They showed that $\mathrm{Fr}_{\mathrm{d}}$ and $\mathrm{X} / \mathrm{D}_{\mathrm{o}}$ were the most important parameters in determining the formation of the scour type (Fig. 6). 


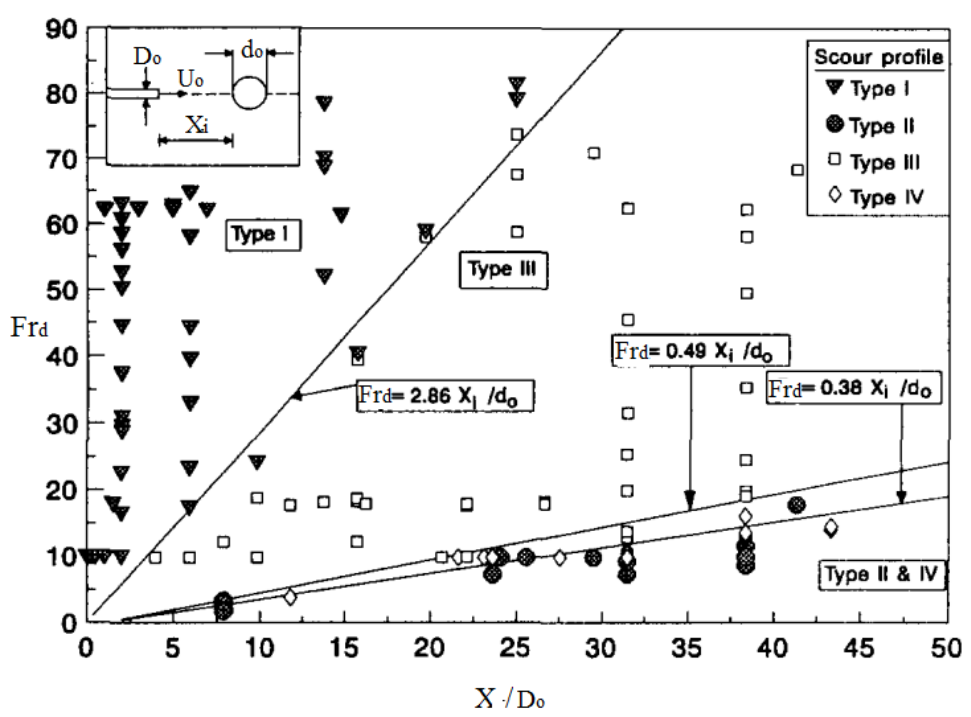

Figure 6. Classification of scour profiles (Chin et al., 1996).

where, $\mathrm{X}$; the distance of pile from propeller face (impingement distance), $\mathrm{Fr}_{\mathrm{d}}$; densimetric Froude number, $\mathrm{D}_{0}$; diameter of circular jet.

Different types of profile with changing values of impingement distances as seen in Fig. 7. Evoluation of the scour profiles have 4 different profile types. Type 1 profile has a maximum scour depth at the toe of pile. Type 2 profile occurs with larger distance of pile from the jet so the effect of pile is not observed and the profile has similarities as without pile conditions.

Type 3 profile has two distinct regions which one of them extends from the jet exit to some distance to in front of a pile and has similarities with type 2 profile and the other region define as scour hole around the pile which has similarities to Type 1 profile. Type 4 profile schematized with a pile located at the deposition zone and the scour zone has similar to Type 2 and maximum scour occurs at the scour zone. Also, Type 2 and 4 profiles formation developed under jet diffusion mechanism while Type 1 and 3 profiles are affected due to pile obstruction mechanism (Fig. 7).

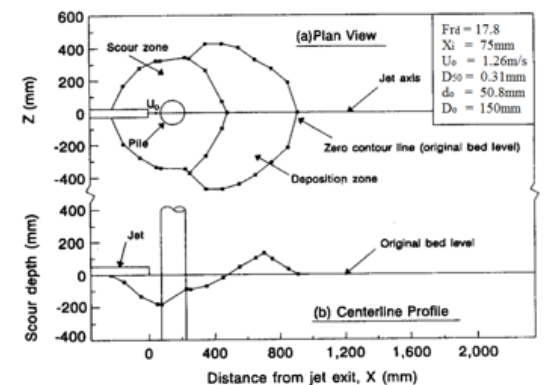

(a)

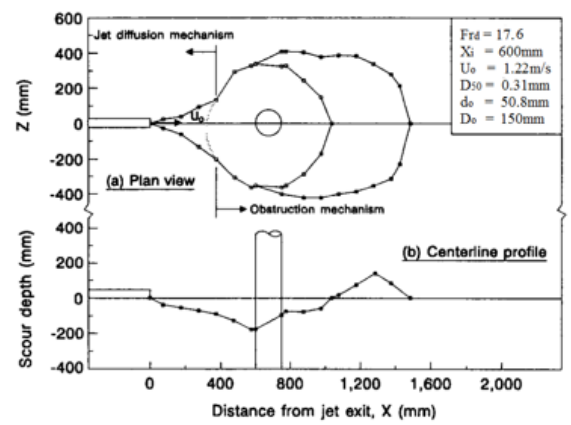

(c)

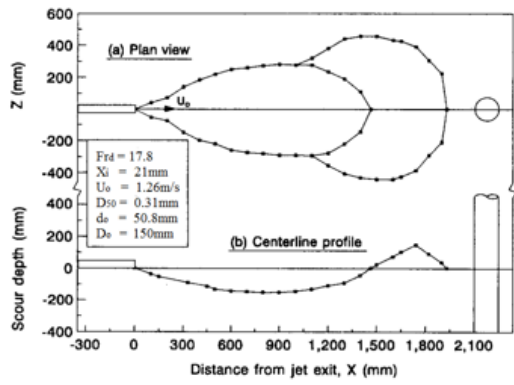

(b)

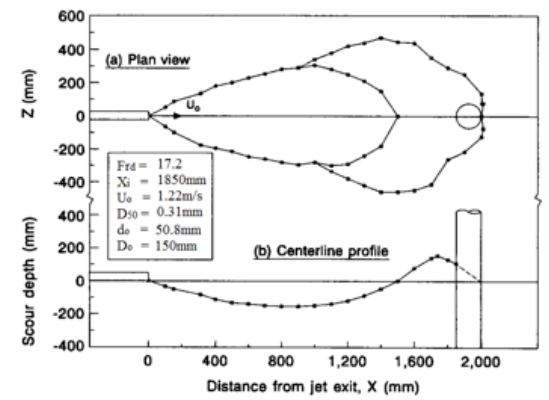

(d)

Figure 7. Scour profile types with pile cases (a) Type 1, (b) Type 2, (c) Type 3, (d) Type 4 (Chin et al., 1996). 
The aim of this study is to understand the evoluation of scour mechanism both with pile and without pile obstructions under propeller jet flow instead of using circular jet. In addition, varying distances of pile from the propeller face were investigated to understand the predominant mechanism effective on evoluation of scour profile. Present study also aims to find out if there is a descriptive location of a pile on the formation of scour hole.

\section{EXPERIMENTAL STUDY}

Experiments were carried out in a rectangular flume which all sides of the flume was made of glass with total length of $6.05 \mathrm{~m}$, width of $1.42 \mathrm{~m}$ and depth of $1.0 \mathrm{~m}$ in the Hydraulics and Coastal Engineering Laboratory of the Civil Engineering Department at Y1ldız Technical University (Fig. 8).

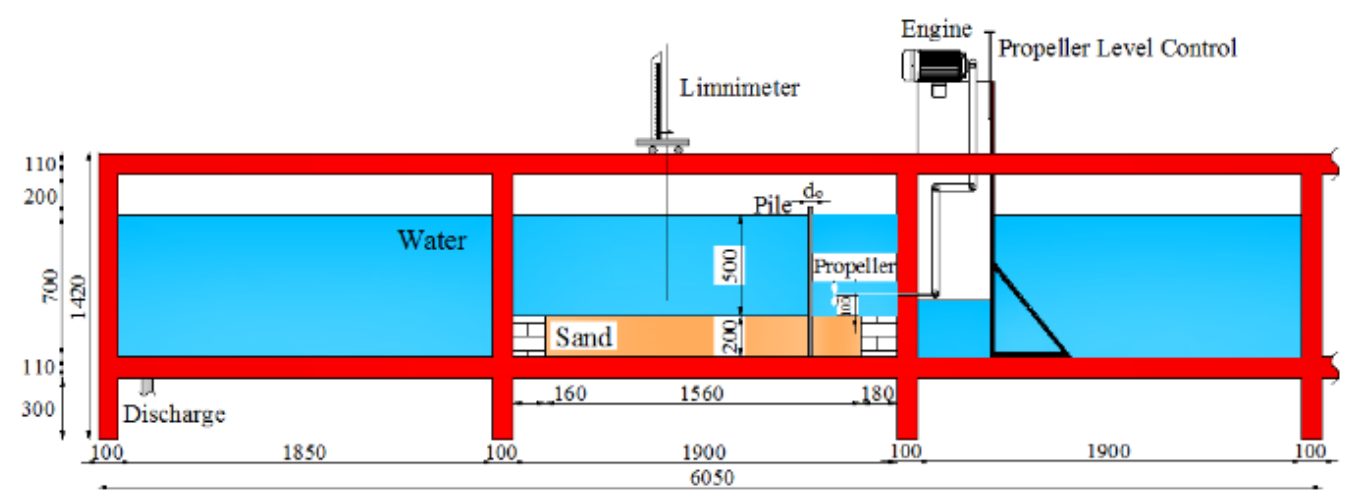

Figure 8. Schematic view of experimental setup in millimeter (Plan view).

The working section in the tank constructed with $0.3 \mathrm{~m}$ deep, $1.56 \mathrm{~m}$ long, and $1.42 \mathrm{~m}$ wide sediment between false floors at each end. The tank was slowly filled without disturbing sand bed. The propeller was turned on when the water level reached to a constant height (h) of $0.50 \mathrm{~m}$ water above the bed. A direct current electric motor was employed to rotate the propellers at constant speeds. The motor was fitted at the upper part of a glass box system and belts were used to rotate the propeller.

Once the motor was switched on, the motor transferred the torque force with belt system in the box to rotate the propeller with different rotation speeds, so rotational speed was adjusted using the speed meter during the experiment. Also glass box system, was designed to adjust the distance between the propeller shaft and the sand bed $(\mathrm{G})$, onto a movable platform. The scour formations was measured with a limnimeter at the end of the experimental test to consider the evoluation of scour hole with pile confinement.

A series of experiments were tested on uniformly distributed sand bed with a median grain size of $\mathrm{d}_{50}=1.28 \mathrm{~mm}$ to understand the local scour mechanism around the pile under propeller jet flow with determined experimental parameters such as; gap which is the height between sand bed and propeller axis propeller speed in round per minute $(\mathrm{rpm}),(\mathrm{G})$, propeller diameters $\left(\mathrm{D}_{\mathrm{p}}\right)$, jet velocities $\left(\mathrm{U}_{\mathrm{o}}\right)$ and horizontal distances of the pile from the face of propeller $(\mathrm{X})$ and pile diameter $\left(\mathrm{d}_{\mathrm{o}}\right)$. Defined parameters are schematized in Fig. 9.

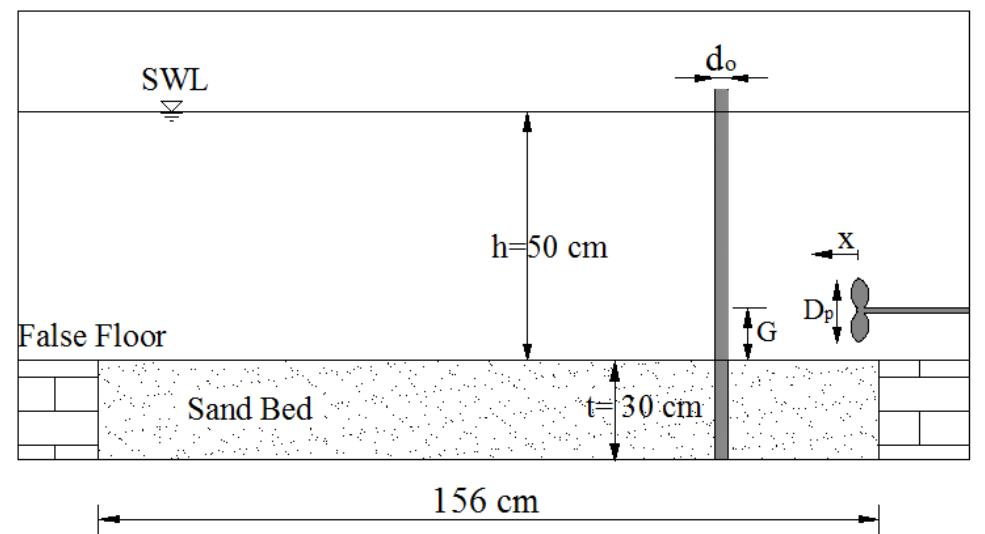

Figure 9. Schematic view of the experimental setup and defined parameters. 


\section{RESULTS AND DISCUSSIONS}

The measurements of a scour profiles are obtained from tested results under experimental conditions such as constant water level at $0.5 \mathrm{~m}$ and propeller height from sand bed $(\mathrm{G})$ at $10 \mathrm{~cm}$,

Propeller with diameter $\left(D_{\mathrm{p}}\right) 10 \mathrm{~cm}$ used in the experiments, adjusted to a constant rotation speed at $660 \mathrm{rpm}$ measured with speed meter. Under these conditions Fig.10 shows two typical scour profiles induced by propeller wash around the pile with diameter $d o=4 \mathrm{~cm}$ and without pile case. Figure 11 shows the effect of pile obstruction.

Small scour beneath the propeller developed less and the length of primary scour decreases for pile existing conditions when compared without pile cases under same experimental conditions such as same propeller diameter, rotation speed and gap (Fig. 11). Also the position of deposition crest moved to upstream with pile case when compared without pile scour profile.

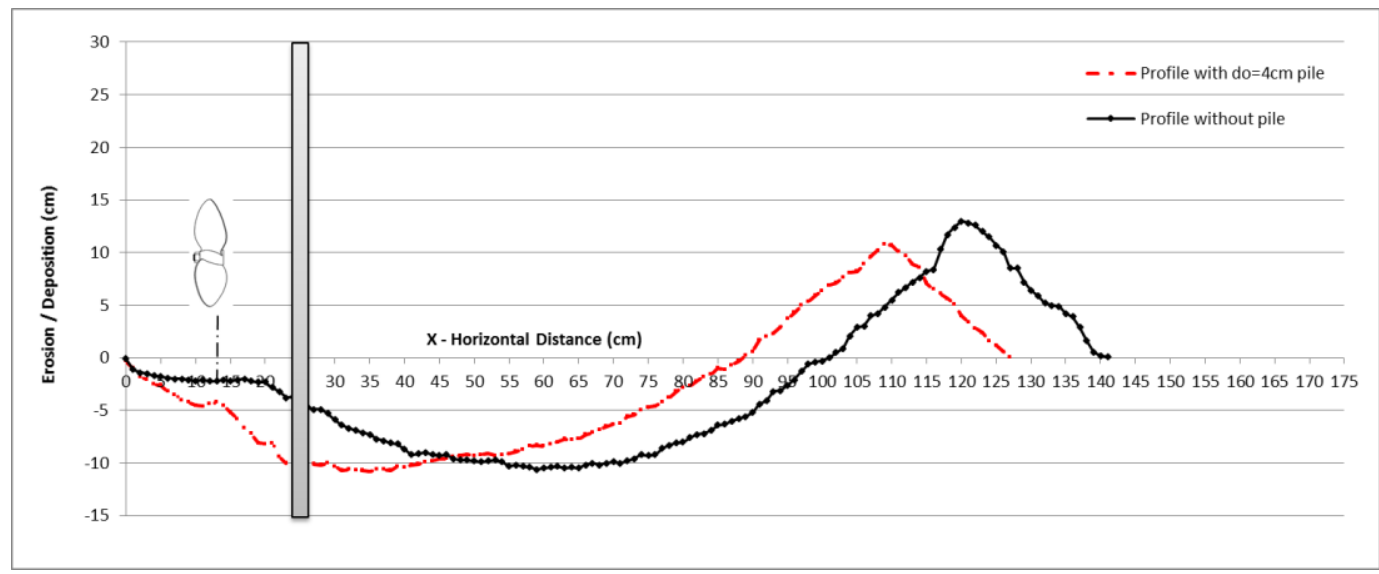

Figure 10. Scour profiles obtained from test results.

The observations from the test showed that the evoluation of scour profile without pile case has same scouring processes defined by Hong et al. (2013) (Fig. 11).

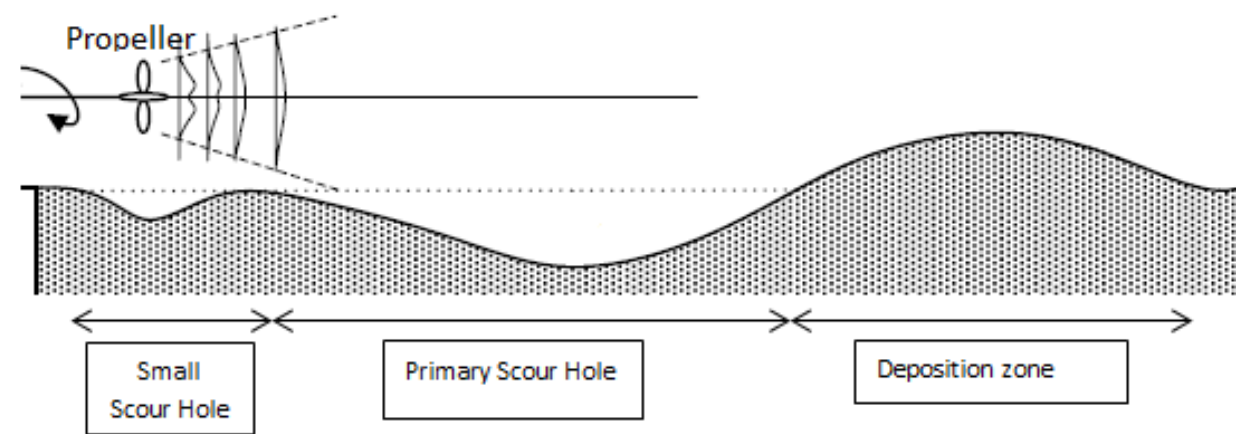

Figure 11. Schematic layout of scouring formation without pile case (Hong et al., 2013).

Without pile scour profiles for each experimental tests were obtained when the scour formations reached at asymptotic stages. Both primary and small scour hole were formed as seen in Fig. 11. However, these stages were not occurred with pile obstructed cases. Instead, the existence of a pile cause scour hole at the base of pile at first and then this hole was showed an increment through the upstream of the pile, so small scour hole formation were not clearly observed beneath the propeller. Because, obstruction of a pile causes down-flow at the face of pile and then horseshoe vortex at the base occurs which is significantly different mechanism when compared with no pile situation.

Pile obstructed profiles are categorized as Chin et al. (1996)'s definition according to $\mathrm{Fr}_{\mathrm{d}}$ and $\mathrm{X} / \mathrm{D}_{\mathrm{o}}$ parameters for circular jet. So different values of $\mathrm{X}$ is tested under same conditions of propeller diameter, gap and rotation speed with $\mathrm{Fr}_{\mathrm{d}}$ is 9.67 in this study.

According to different locations of a pile from the propeller face has different formation of scour profiles. Fig. 13 shows the scour profile over the sand bed without pile and maximum equilibrium scour depths at the toe of piles diameter of $d_{0}=4 \mathrm{~cm}$ also marked on this Figure with changing values for the 
pile location (X) as $2.5 d_{0}, 5 d_{0}, 7.5 d_{o}$ and $10 d_{o}$ apart from the propeller face while gap is constant at $10 \mathrm{~cm}$.

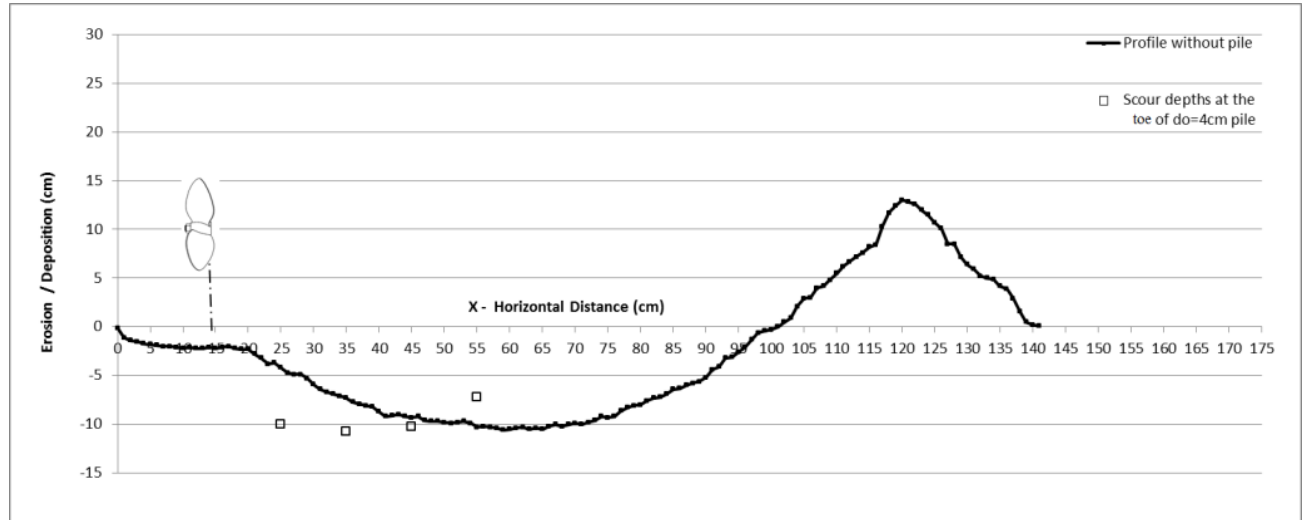

Figure 12. Scour profile without pile obstruction and scour depths at the toe of pile for its different locations $\left(X=2.5 d_{o}, 5 d_{o}, 7.5 d_{o}\right.$ and $\left.10_{d o}\right)$.

In the present study, increasing distance of pile from the propeller was caused lower scour depths at the toe of pile. Experiments showed that the pile location with respect to the distance from the propeller face was also descriptive for scour dimensions. Scour profiles over the sand bed were not affected after the distances at $X / D_{p}=3$ and $X / d_{o}=7.5$ with propeller diameter of $D_{p}=10 \mathrm{~cm}, F_{d}=9.67$ and $G=10 \mathrm{~cm}$ (Fig.13).

The scour profiles obtained from this study showed similar scour formations as type 1 and type 3 which is defined by Chin et al. (1996)'s (Fig. 7). According to classification given by Chin et al. (1996) in Fig. 6, the boundary values between type 1 and type 3 scour profile formations were calculated under experimental conditions using $\mathrm{D}_{\mathrm{o}}=10 \mathrm{~cm}, \mathrm{Fr}_{\mathrm{d}}=9.67$ and $\mathrm{d}_{\mathrm{o}}=4 \mathrm{~cm}$. These conditions were assumed to represent similar experimental conditions defined in this study. The results showed that $\mathrm{X} / \mathrm{d}_{\mathrm{o}}=3.38$ and $\mathrm{X} / \mathrm{D}_{\mathrm{o}}=1.35$ are the boundary values between type 1 and 3 formations according to Chin et al. (1996). Also predominant cause of the scour hole is pile obstruction mechanism before distance at $X=3.38 \mathrm{~d}_{\mathrm{o}}$ and $\mathrm{X}=1.35 \mathrm{D}_{\mathrm{o}}$. After the distance at $\mathrm{X}=3.38 \mathrm{~d}_{\mathrm{o}}$ the effective mechanism on scour profile is due to jet mechanism.

However, this study showed that the effective pile location is at $X=3 D_{p}$ and $X=7.5 d_{o}$ under propeller jet mechanism while the effective location was calculated at $X=1.35 D_{0}$ and $X=3.8 d_{0}$ according to Chin et al. (1996)'s. This value is 2.2 times less than the values obtained from this study for propeller jet case. Because the mechanism of a propeller and circular jet has different effects on scour formations and also there is a gap between the propeller and sand bed which is $10 \mathrm{~cm}$ while the circular jet is located on the sediment bed.

\section{CONCLUSIONS}

This study investigate the evoluation of the scour hole around pile under propeller jet mechanism on a uniform cohesionless sediment bed experimentally. Experimental conditions such as propeller speed at $660 \mathrm{rpm}$, water level at $50 \mathrm{~cm}$, propeller diameter with $10 \mathrm{~cm}$ and gap at $10 \mathrm{~cm}$ keep constant while the distance of the pile from the propeller face has varying values of $2.5 \mathrm{~d}_{\mathrm{o}}, 5 \mathrm{~d}_{\mathrm{o}}, 7.5 \mathrm{~d}_{\mathrm{o}}$ and $10 \mathrm{~d}_{\mathrm{o}}$. Based on experimental data analyses the following conclusions given;

1. Evoluation of the scour formations has a significant differences with and without pile obstruction. Because the existence of a pile can cause pile vortex mechanism.

2. The existence of the pile causes a decrease of the scour length and increase of the scour depth at the toe of the pile when it compared without pile obstruction.

3. Different pile locations was also descriptive for scour dimensions. The pile were not effective on scour profiles over the sand bed after distance at $X=3 D_{p}$ (or $X=7.5 d_{o}$ ). The main distinctive mechanism effective on scour profile is due to the pile before the distance at $\mathrm{X}=3.38 \mathrm{~d}_{\mathrm{o}}$ (or $\mathrm{X}=1.35$ $\mathrm{D}_{\mathrm{o}}$ ) according to Chin et al. (1996)'s.

4. The distance of the effective location found by Chin et al. (1996)'s is 2.2 times less than the values obtained from this study. Because the mechanism of a propeller and circular jet has different effects on scour formations and also the gap between the propeller and sand bed is $10 \mathrm{~cm}$ while the circular jet is located on the bed. 


\section{REFERENCES}

Hong, J.H., Chiew Y.M., Cheng N.S. 2013. Scour Caused by a Propeller Jet, Journal of Hydraulic Engineering, ASCE, 139:1003-1012.

Akib S., Jahangirzadeh A., Basser H. 2014. Local scour around complex pier groups and combined piles at semi-integral Bridge, J. Hydrol. Hydromech.,62, 2014, 2, 108-116.

Chin C.O., Chiew Y. M., Lim S. Y, Lim F. H. 1996. Jet Scour Around Vertical Pile, J. Waterway, Port, Coastal, Ocean Eng., 122:59-67.

Yüksel Y., Kayhan S., Çelikoğlu Y., Cihan K. 2012. Open Type Quay Structures Under Propeller Jets, ICCE 2012, Santander, Spain.

Lam W., Hamill G.A., Robinson D.J., Raghunathan S. 2011. A rewiev of the equations used to predict the velocity distrubition within a sihp's propeller jet, Applied Ocean Research, 38:1-10.

Albertson M. L and Jensen R. A. 1951. Diffusion on Submerged Jet, Transactions of the American Society of Civil Engineers, 1950, Vol. 115, 665-693.

Van Rijn L. C. 2013. Local Scour near Structures, www.leovanrijn-sediment.com, 29.03.2015. 